\title{
ANÁLISE DO COMPORTAMENTO HIDROLÓGICO DA BACIA CÓRREGO SUJO, TERESÓPOLIS (RJ)
}

\author{
Paula Coelho Araujo ${ }^{(a)}$, Suelen Oliveira Alpino Rodrigues ${ }^{(b)}$, Vítor dos Santos Costa ${ }^{(c)}$, \\ André de Souza Avelar ${ }^{(\mathrm{d})}$
}

aa Departamento de Geociências/ Universidade Federal do Rio de Janeiro, plcaraujo@hotmail.com
b Departamento de Geociências/ Universidade Federal do Rio de Janeiro, sualpino@yahoo.com.br
cDepartamento de Geociências/ Universidade Federal do Rio de Janeiro, vitordsc2@ @otmail.com
${ }^{\mathrm{d}}$ Departamento de Geociências/ Universidade Federal do Rio de Janeiro,andre.avelar@globo.com

\section{EIXO: BACIAS HIDROGRÁFICAS E RECURSOS HÍDRICOS: ANÁLISE, PLANEJAMENTO E GESTÃO}

\begin{abstract}
Resumo
Sabe-se que atividades humanas interferem no ciclo hidrológico, causando a degradação qualitativa e reduzindo as potencialidades hídricas. Este trabalho objetiva entender o comportamento da vazão e determinar a curva chave da bacia do Córrego Sujo. Para tal, foi realizado o monitoramento fluviométrico (vazão e altura linimétrica) no baixo, médio e alto curso da bacia e a mensuração da precipitação. Foram gerados gráficos que mostram a relação entre a precipitação e cotalinimétrica e as curvas-chaves das estações monitoradas. Os resultados apontaram que entre os meses de maio a setembro os canais fluviais atuam no fluxo de base, necessitando de políticas de planejamento, uma vez que já existem conflitos entre os agricultores pelo uso da água. Todavia, a estação Médio Curso mostrou-se a mais ajustada, ou seja, a que apresentou um coeficiente de correlação elevado na relação cotavazão, gerando confiabilidadepara futuras extrapolações da curva.
\end{abstract}

Palavras-chaves: Fluviometria; Cota-vazão; Curva-chave; Gestão hídrica.

\section{1) Introdução}

Diante do contexto atual, verifica-se que as atividades humanas estão interferindo nas etapas do ciclo hidrológico causando a degradação qualitativa e reduzindo as disponibilidades hídricas. Estas questões, por sua vez, irão acarretar perdas que interferem no seu uso. Posto isto, a ciência - de caráter interdisciplinar,está fomentando pesquisas de cunho quantitativo e qualitativo, a fim de subsidiar a gestão dos recursos hídricos.

Nesse a Política Nacional de Recursos Hídricos, Lei no 9.433/97, também denominada de Lei das Águas do Brasil, objetiva adotar medidas para o uso racional da água, assegure a qualidade da mesma e haja prevenção contra eventos hidrológicos críticos. Assim, os estudos hidrométricos permitem conhecer o regime hidrológico de uma determinada área de estudo, atuando como uma ferramenta de gerenciamento fundamental para a gestão de recursos hídricos.

Magalhães Júnior (2000) retrata que para o sucesso de qualquer sistema de gestão das águas é imprescindível um plano de monitoramento adequado, que permita compor um banco 


$\begin{aligned} & \text { XVII Simpósio Brasileiro } \\ & \text { de Geografia Fisica Aplicada }\end{aligned}$
$\begin{aligned} & \text { I Congresso Nacional } \\ & \text { de Geografia Física }\end{aligned}$

de dados subsidiando a geração de informações e viabilizando projetos de investimentos em recursos hídricos. Considerando que, não se pode gerenciar aquilo que não se conhece e não possui informações. É preciso, portanto, quantificar para compreender os estoques hídricos, entender o comportamento hidrológico e as alterações no uso da água.

A fluviometria, então, é uma ferramenta importante para a gestão dos recursos hídricos, já que está atrelada às alterações da altura linimétrica, ou seja, aos registros das alturas das lâminas d'água em um rio, assim como as vazões obtidas na seção transversal do canal fluvial, durante um determinado período de tempo. Desta forma, é possível através desta metodologia monitorar as alterações provocadas no fluxo da água, que podem com o tempo, vir a modificar os componentes do corpo hídrico. Estes dados são também essenciais para o estudo, uma vez que possibilita conhecer o comportamento hidrológico de um determinado corpo hídrico frente às mudanças sazonais e, de acordo com Allan (1995), pode-se estimar, algumas variáveis qualitativas, como por exemplo, os padrões de concentração com o deflúvio.

A área de estudo do desenvolvimento da pesquisa é a bacia hidrográfica do Córrego Sujo, da qual está localizada no distrito de Venda Nova, município de Teresópolis - RJ, abrange 53,5 $\mathrm{Km}^{2}$ de extensão (conforme a figura I). Possui as coordenadas $22^{\circ} 15^{\prime}-22^{\circ} 10^{\prime} \mathrm{S}$ de latitude e 42 $55^{\prime}-42^{\circ} 45^{\prime}$ W de longitude (UTM: 0720000/7534000 e 0720000/7546000). O Córrejo Sujo corresponde ao canal principal da bacia e é tributário direto do rio Preto, este por sua vez drena para o rio Piabanha, que posteriormente deságua no rio Paraíba do Sul.

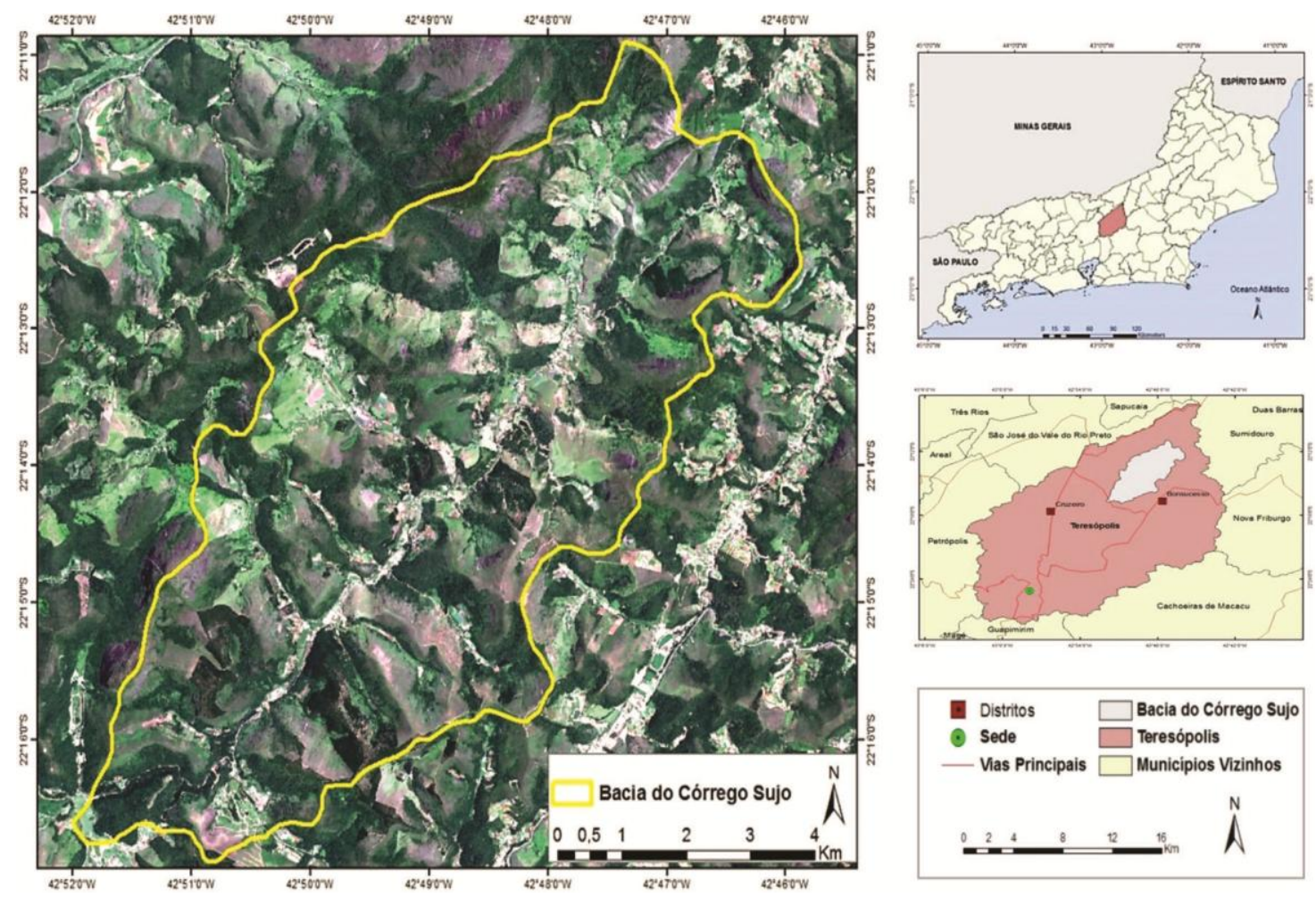

Figura I - Mapa de localização do município de Teresópolis - RJ. 


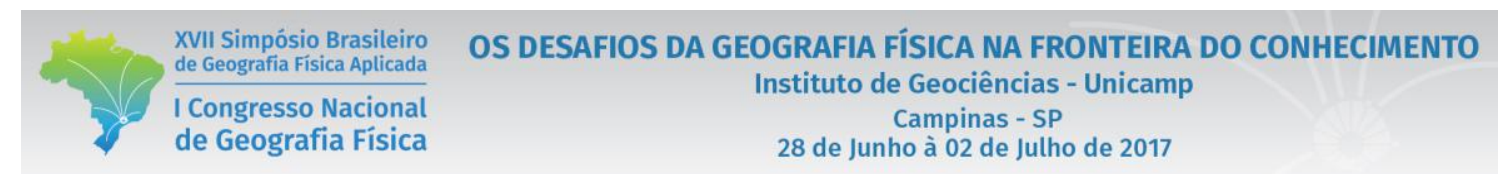

A atividade econômica predominante na bacia é a produção agrícola irrigada, com elevada inserção de insumos químicos e conforme Brum (2010) já existem conflitos pelo uso da água entre os moradores locais pelo uso da água, justificando-se assim pesquisas quantitativas buscando compreender as disponibilidades hídricas da bacia.

Segundo as "Normais Climatológicas do Brasil 1961 -1990" /INMET, o clima do município de Teresópolis apresenta características bem definidas, marcado por um período mais quente e chuvoso e outro seguido de estiagem e temperaturas mais amenas, com média anual de temperatura de $17,7^{\circ} \mathrm{C}$ (figura II).

O processo de ocupação humana bacia foi possível devido ao planalto reverso da Região Serrana, que no caso de Teresópolis, a população se assentou nos alvéolos intramontanos na bacia do rio Paquequer, desenvolvendo como atividade econômica a agricultura, cultivada nos fundos de vales e em baixas encostas dos relevos menos acidentados nos vales dos rios.Geologicamente, a bacia se assenta na Unidade Serra dos Órgãos, apresentando a seguinte composição: "hornblenda - biotita granitóide de granulação grossa e composição expandida de tonalítica a granítica, composição cálcio - alcalina" (DANTAS, 2000).

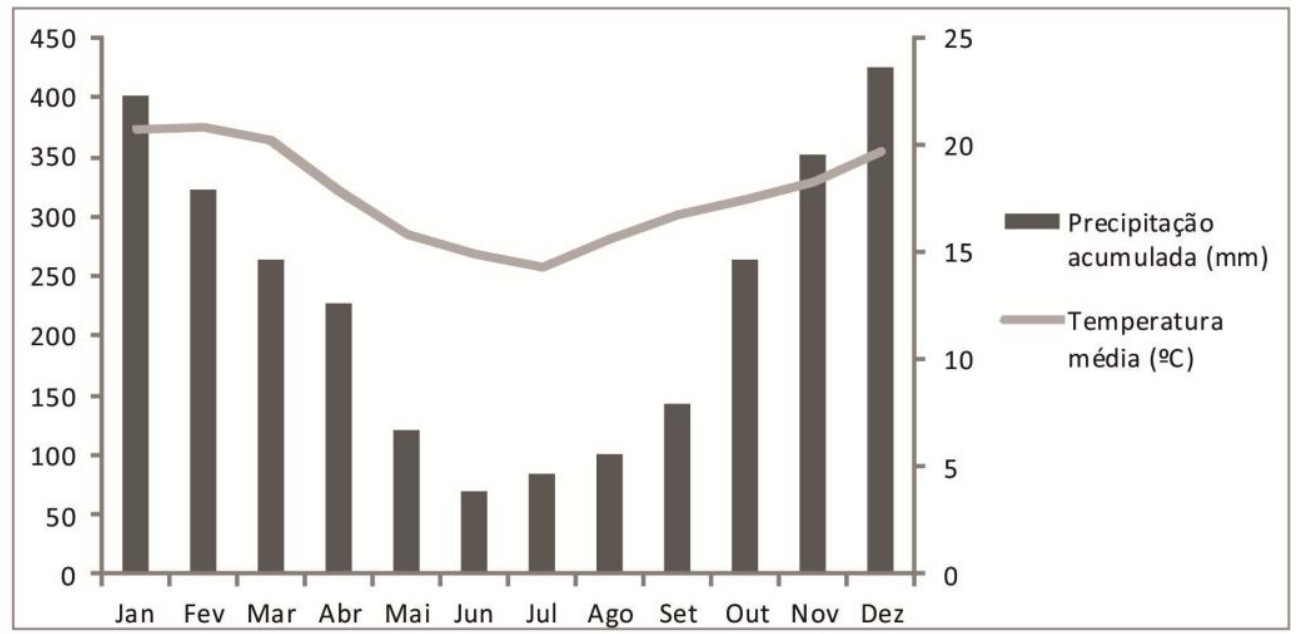

Figura II - Temperatura média compensada e precipitação acumulada de Teresópolis, entre os anos de 1961-1990. Fonte: INMET (2009).

De acordo com Barreto (2005) o solo da bacia apresenta as seguintes classes: Latossolo Bruno Distrófico, CambissoloHáplicotb Distrófico, NeossoloFlúvicotb distrófico, NeossoloLitólicoEutófico, ChernossoloArgilúvicoÓrtico e ArgissoloAcizentado Distrófico. Já vegetação é representada pelos remanescentes da Mata Atlântica, nas formações Montana e Antimontana, podendo encontrar também vegetação secundária em diversos estágios sucessionais. 
Conforme Araujo (2013),o uso e cobertura do solo da bacia são compostos predominantemente por áreas de gramínea $(24,02 \%)$ e pela silvicultura $(16,40 \%$, este valor elevado representa o estímulo ao cultivo do produto devido à lucratividade do produto).

Posto isto, esta pesquisa tem por objetivo entender o comportamento das descargas hídricas dos canais fluviais e determinar a curva - chave da bacia do Córrego Sujo, através de mensurações fluviométricas, gerando um instrumento que poderá auxiliar as instituições governamentais, o comitê de bacia e os agricultores na tomada de decisão.

\section{2) Material e métodos}

\section{1)Fluviometria}

Para a realização do estudo foram feitas asleiturasda régua, a mesma pode ser realizada através do observador de campo ou aparelho contendo um sensor denível d'água acoplado em datalogger. No entanto, neste estudo foram utilizados os dados coletados pelo leitor de campo, devido aos problemas apresentados pelo software.

Nesse sentido, foram instalados na bacia do Córrego Sujo três estaçõesfluviométricas: Estação Sorvete (baixo curso), Estação CPRM (baixo curso) e Estação Ponte Gilberto (alto curso), conforme figura III. Com relação às réguas, as mesmas contém uma escalalinimétrica e foram fixadas nas margens do canal fluvial, sendo suficientes para medir asvariações da água na seção. A leitura de cada régua foi realizada diariamente nos horários de 7:00 e17:00 por um morador local, sendo que na Estação Sorvete (baixo curso) foi inserido odatalogger que registrava os dados obtidos de 10 em 10 minutos. 


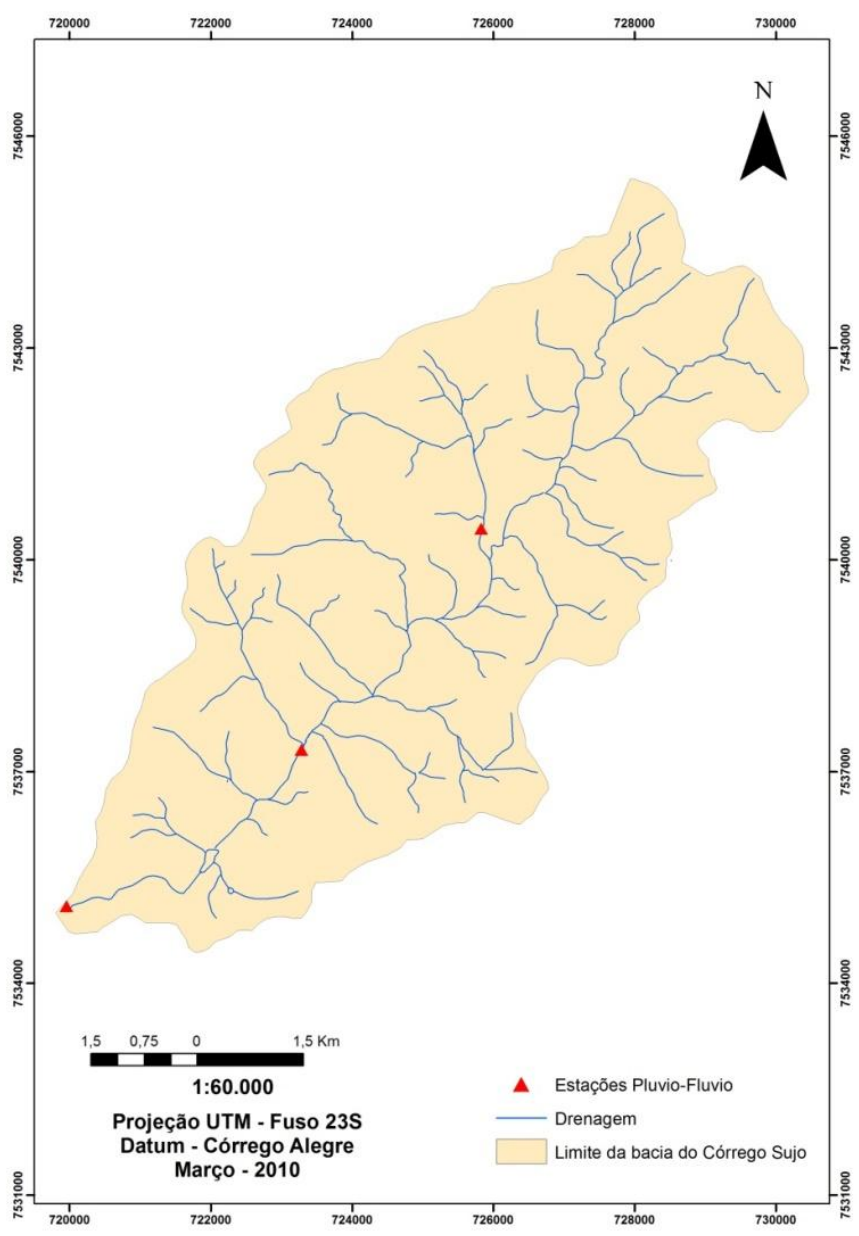

Figura III - Mapa de localização das estações fluviométricas na bacia do Córrego Sujo. Fonte: BRUM, 2010.

No que tange a descarga fluvial, Santos et al. (2001) a conceitua como "a vazão ou descarga de um rio é o volume de água que passa através de uma seção transversal na unidade de tempo (em geral um segundo)". Desta forma, para a aferição da vazão existem diversos métodos que se adequam melhor ao fluxo d'água, nesta pesquisa foi utilizado o micro molinete hidrométrico Global Water FP 201, que determina a área da seção e a velocidade média do fluxo, do qual passa nesta seção.

Desta forma, neste molinete hidrométrico as vazões são calculadas multiplicando-se a velocidade média na vertical pela profundidade na vertical multiplicada pela soma das semidistâncias às duas verticais adjacentes. Em detrimento da variação da velocidade no fluxo fluvial, já que esta é maior na parte central do canal em relação às margens, foram obtidos diversos pontos na seção transversal (SANTOS et al., 2001).

As medições foram realizadas mensalmente nas três estações já mencionadas, considerando o período de seca e estiagem. O método empregado foi o da meia-seção, do qual será representado seus respectivos procedimentos de cálculos. 
A fim de obter o cálculo da descarga líquida adotou-se a metodologia procedente:

Cálculo das velocidades médias nos segmentos:

$$
\begin{aligned}
& \overline{\mathrm{v}_{(\mathrm{a} 1)}}=\left(\overline{\mathrm{v}_{(1)}}+\overline{\mathrm{v}_{(2)}}\right) / 2 \\
& \overline{\mathrm{v}_{(\mathrm{a} 2)}}=\left(\overline{\mathrm{v}_{(2)}}+\overline{\mathrm{v}_{(3)}}\right) / 2
\end{aligned}
$$

Cálculo das áreas dos segmentos:

$$
\begin{aligned}
& \mathrm{a}_{1}=\left(\mathrm{d}_{2}-\mathrm{d}_{1}\right) *\left[\left(\mathrm{p}_{2}+\mathrm{p}_{1}\right) / 2\right] \\
& \mathrm{a}_{2}=\left(\mathrm{d}_{3}-\mathrm{d}_{2}\right) *\left[\left(\mathrm{p}_{3}+\mathrm{p}_{2}\right) / 2\right]
\end{aligned}
$$

Cálculo das vazões nos segmentos:

$$
\begin{aligned}
& \mathrm{q}_{\mathrm{a} 1}=\overline{\mathrm{v}_{\mathrm{a} 1}} * \mathrm{a}_{1} \\
& \mathrm{q}_{\mathrm{a} 2}=\overline{\mathrm{v}_{\mathrm{a} 2}} * \mathrm{a}_{2}
\end{aligned}
$$

Cálculo da vazão total:

$$
\mathrm{Q}=\sum \mathrm{q}_{\mathrm{i}}
$$

Cálculo da área total:

$$
A=\sum a_{i}
$$

Cálculo da velocidade média:

$$
\overline{\mathrm{V}}=\mathrm{Q} / \mathrm{A}
$$

Cálculo da largura do rio:

$$
\mathrm{L}=\mathrm{d}_{\mathrm{n}}-\mathrm{d}_{1}
$$

Cálculo da profundidade média do rio:

$$
\mathrm{P}=\mathrm{A} / \mathrm{L}
$$

\section{2) Precipitação}

A mensuração da precipitação baseia-se na altura pluviométrica (ou altura de precipitação, que em geral é expressa em milímetros) e na quantidade de água que cai por unidade de área horizontal (DERISIO, 2012). 
As medições deste parâmetro, em geral, são realizadas por pluviômetros e pluviógrafos. Nesse sentido, a fim de entender o regime de chuvas na bacia estudada, foram empregados três pluviômetros convencionais denominados de "Ville de Paris", situado no baixo, médio e alto curso da bacia.

As medições foram também feitas por um morador residente próximo aos equipamentos, que realizava a leitura diariamente. Ainda assim, foram obtidos dados a cada 15 minutos, na estação automática, que era descarregada mensalmente.

\section{3) Resultados e discussão}

\section{1) Relação entre precipitação e altura linimétrica}

As estações fluvimétricas foram monitoradas durante um ano hidrológico, no período de 01 de dezembro de 2011 a 30 de novembro de 2012. Contudo, houve algumas interrupções na leitura devido aos problemas com a régua linimétrica (meses de janeiro e junho na Estação Gilberto - Alto Curso), que necessitou de manutenção e também devido a algumas anotações que não foram realizadas pelo leitor de campo nesta mesma estação.

Observou-se um comportamento simultâneo das variaçõeslinimétricas nas três estações (figurasIV, V e VI), sendo que entre maio e setembro de 2012 foi evidente a ocorrência apenas do fluxo de base de vazão nos canais mínimo, uma vez que as cotas encontraram-se sem grandes variações e em baixos níveis. No entanto, partir do mês de outubro de 2012 verificou-se um aumento da frequência na hidrógrafa e do volume de chuvas, marcando a estação chuvosa, contribuindo para uma elevação na vazão nos respectivos canais.

Na Estação Médio Curso (também denominada de Estação CPRM) ocorreu a partir do mês de abril um declínio da altura linimétrica, atribuindo este fato a dragagem, devido ao acúmulo de sedimentos e frequentes ocorrências de extravazamento do canal, aprofundando-o e o alargando.

Conforme Dunne\&Leopold (1978) a precipitação quando atinge a superfície, tende a ser absorvida pelo solo, contudo quando a umidade do solo estiver suficientemente elevada, a água irá percolar lateralmente no solo em direção aos rios através do escoamento superficial. 


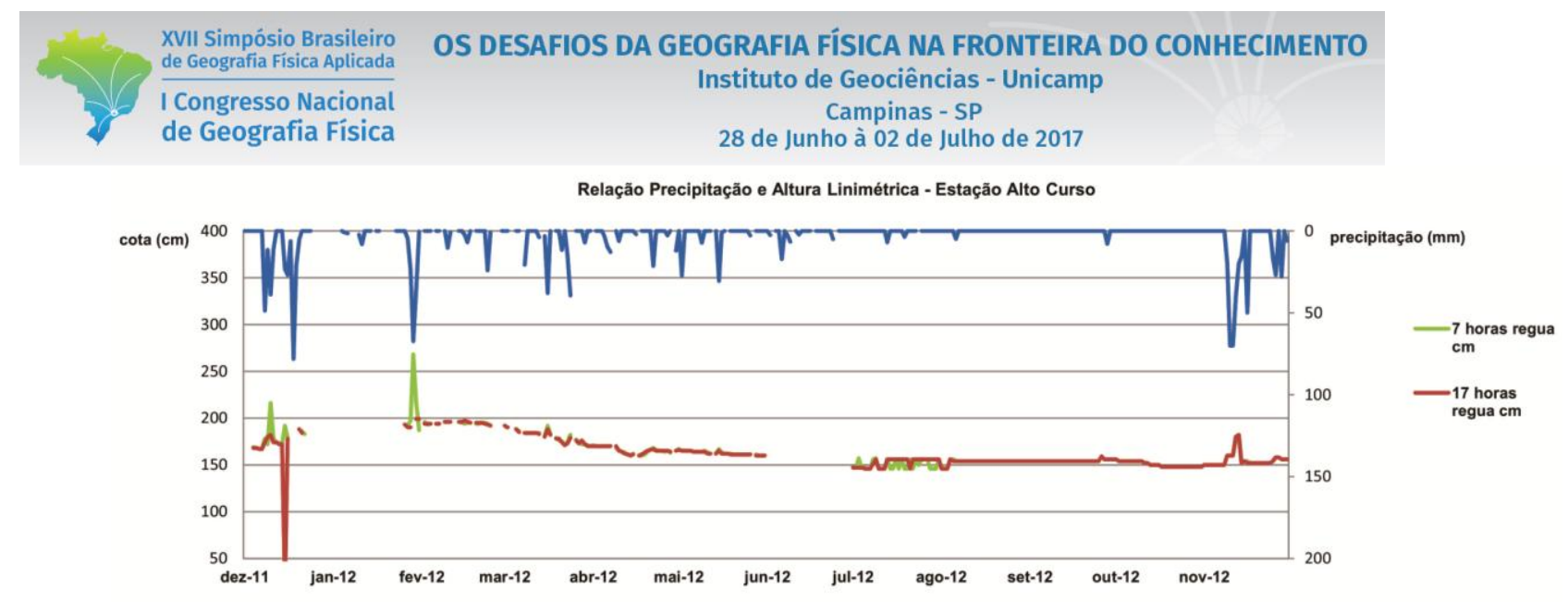

Figura IV: Relação entre precipitação e cota linimétrica na Estação Alto Curso

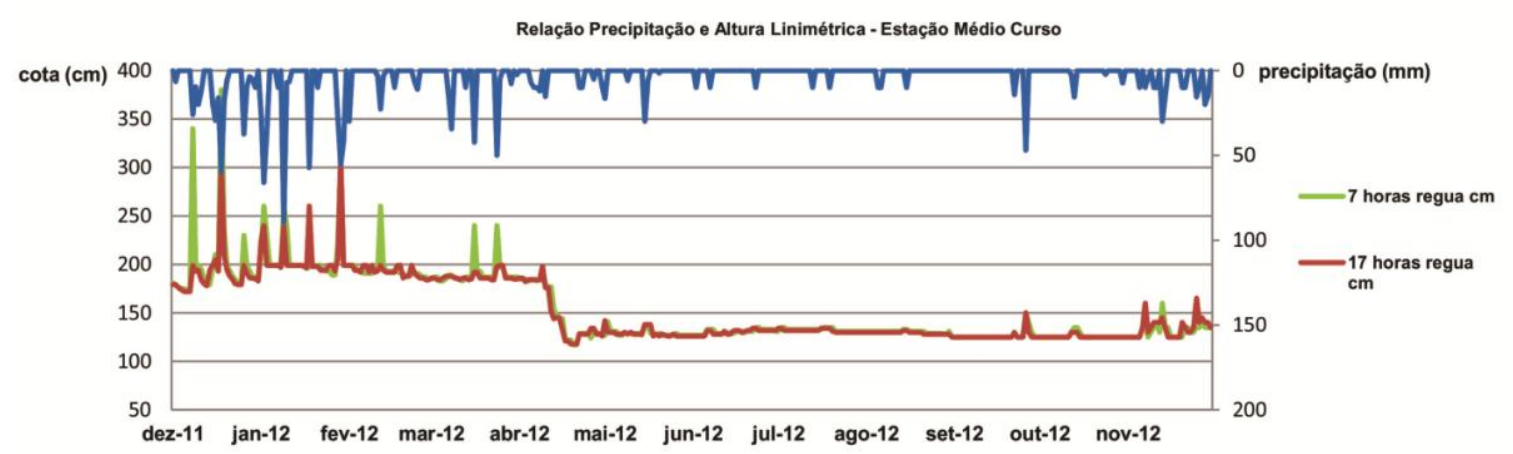

Figura V: Relação entre precipitação e cota linimétrica na Estação Médio Curso

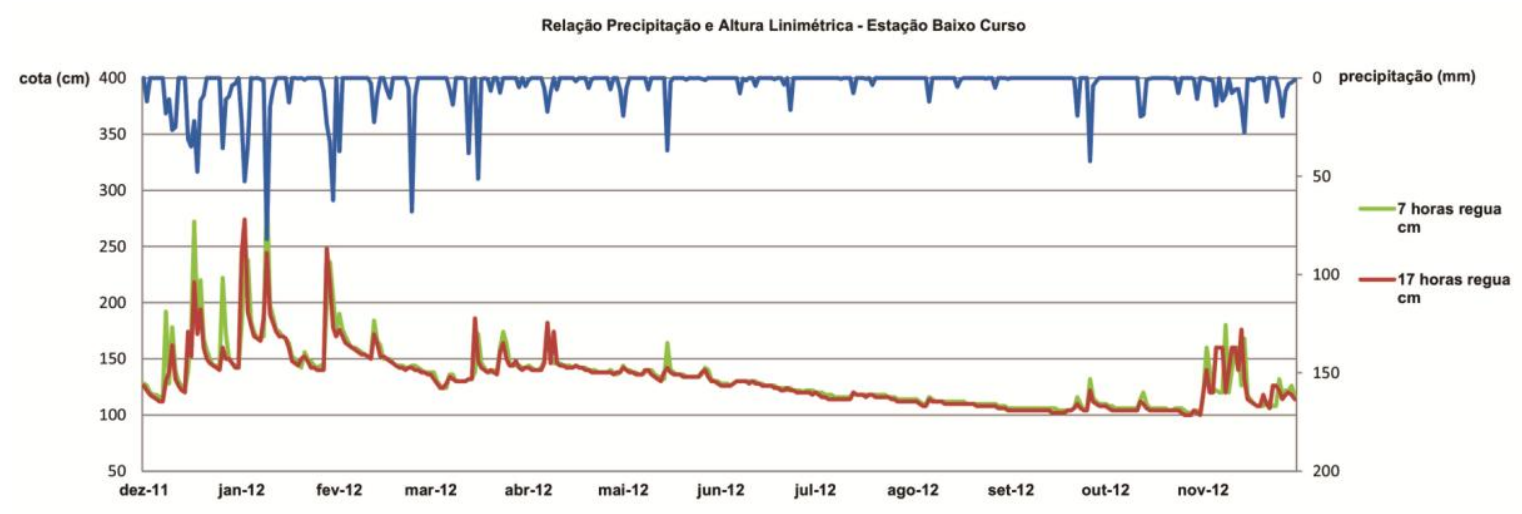

Figura VI: Relação entre precipitação e cota linimétrica na Estação Baixo Curso

Com relação à vazão máxima, não foi observado um dia específico e comum a todas as estações, em que a mesma ocorreu. Na Estação Alto Curso, o maior volume de chuva verificado foi no dia 18/12/2011 com 78,2 mm, sendo que também foi constatado precipitação nos três dias anteriores, contribuindo para a destruição da régua, não sendo possível fazer a leitura da altura da lâmina d'água. Foi então, elencado o segundo maior evento de chuva, que se deu no dia 29/01/2012 apresentando um volume de 67,4 mm, com episódios de precipitação nos dois dias anteriores, que por sua vez, colaboraram para aumentar o grau de saturação do solo, assim como o escoamento superficial. Por conseguinte, a resposta chuva-vazão foi mais rápida e em maior magnitude, sendo perceptível figura IV, a partir da elevação da cota linimétrica. 
Já na Estação Médio Curso, o maior volume de chuva foi observado no dia 09/01/2012 apresentando $89,3 \mathrm{~mm}$, houve precipitação também no dia anterior, porém com um valor bastante inferior, sendo que a vazão não respondeu com a mesma intensidade, podendo afirmar que houve maior infiltração da água no solo, em relação ao escoamento superficial para o canal. $\mathrm{Na}$ Estação Baixo Curso (Estação Sorvete), foi percebido não somente para um dia específico, mas que os meses de dezembro/2011, janeiro e fevereiro/ 2012 apresentaram picos altos e pontiagudos no gráfico contido na figura VI, sendo resultantes da elevada contribuição do escoamento superficial e da baixa absorção de água neste ponto na bacia de drenagem.

3.2) Curva-chave

A curva-chave é uma função que representa a relação entre a vazão e a cota do escoamento (altura linimétrica) em uma seção transversal do canal. A mesma é baseada nos valores de vazão mensurados em campo nas estações secas e chuvosas, permitindo a previsibilidade da vazão de um canal diante de condições adversas, como chuvas intensas ou períodos de estiagem.

A curva-chave da Estação Alto Curso foi definida a fim de estabelecer a relação entre linimetria e vazão foi elaborada uma tabela I e um gráfico (figura VII) representando a Estação Alto Curso. Nos dados selecionados para o estudo obteve-se a vazão máxima de 0,23 m3/s, mensurado no mês de março de 2012. Já a vazão mínima atingiu $0,05 \mathrm{~m} 3 / \mathrm{s}$ e ocorreu no mês de outubro de 2012 com baixos índices de chuva. Com relação à curva-chave da Estação Alto Curso, a mesma está expressa pela equação polinomial de quinto grau: $\mathrm{y}=-6 \mathrm{E}+07 \times 5+4 \mathrm{E}+$ $07 \mathrm{x} 4-1 \mathrm{E}+07 \mathrm{x} 3+1 \mathrm{E}+06 \mathrm{x} 2-63608 \mathrm{x}+1406,1$.

$\mathrm{O}$ coeficiente de determinação (também chamado de $\mathrm{R}^{2}$ ) possui um intervalo de 0 a $1 \mathrm{e}$ quanto maior for seu valor, mais explicativo será o modelo. Nesta pesquisa, o coeficiente de determinação foi elevado, ou seja, apresentou $o R^{2}=0,8624$ (figura VII). Isto significa que, $86,24 \%$ da cota altimétrica é explicada pelo modelo (que corresponde a equação polinomial mencionada).

A princípio empregou-se a equação de quarto grau, no entanto a mesma não se ajustou bem aos dados, resultando em baixos índices de determinação (R2), sendo eles 0,635, 0,411 e 0,673 para as estações Alto, Médio e Baixo Curso, respectivamente. Assim, a equação de quinto grau se ajustou melhor aos dados.

Tabela I: Resultados da altura da lâmina de água e vazão na Estação Alto Curso

\begin{tabular}{ccc}
\hline \hline Data & Altura (cm) & Vazão (m³ $/ \mathbf{s})$ \\
\hline \hline Nov. / 2011 & 174 & 0,12 \\
Jan. / 2012 & 192 & 0,19 \\
Fev. / 2012 & 186 & 0,20
\end{tabular}


Mar. / 2012

28 de Junho à 02 de Julho de 2017

Abr. / 2012

186

0,23

Mai. / 2012

129

0,16

Jun $/ 2012$

134

0,16

Ago. / 2012

131

0,15

Set. / 2012

131

0,07

Out. / 2012

134

0,08

Nov. / 2012

125

0,05

130

0,09

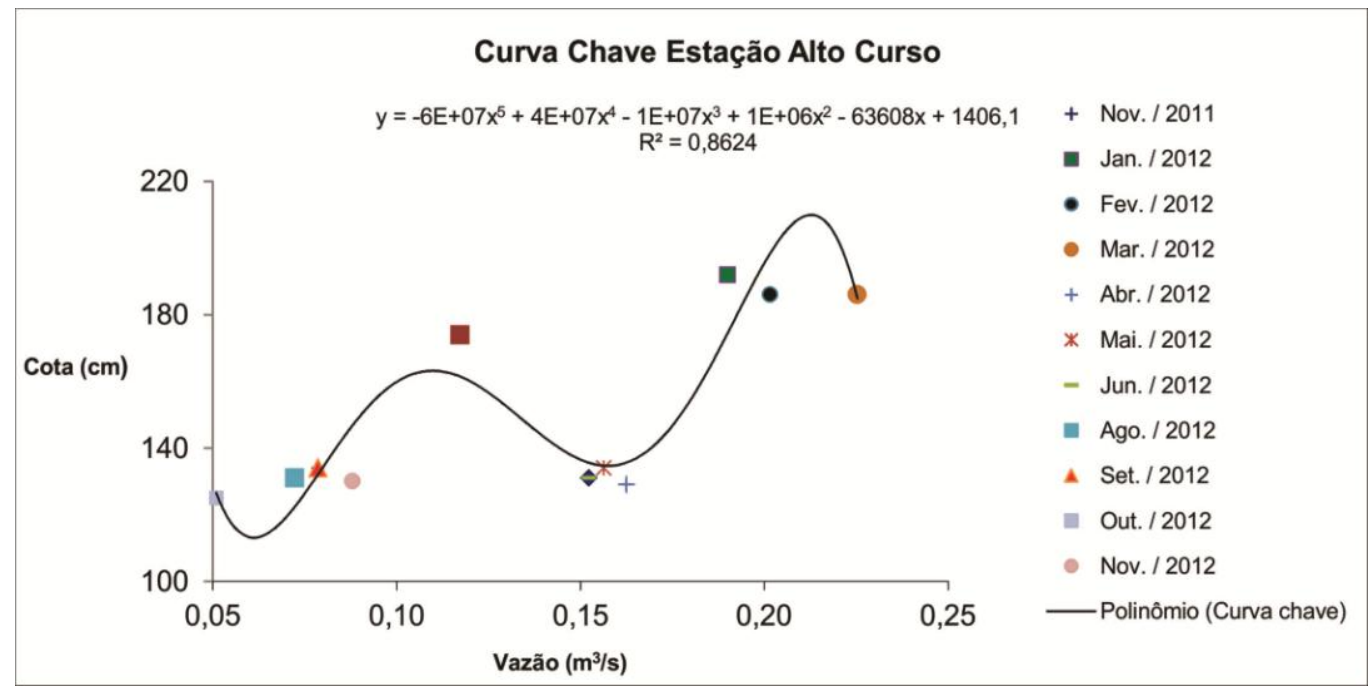

Figura VII: Curva-Chave do tributário do rio Córrego Sujo (Estação Alto Curso)

Em se tratando da Estação Médio Curso, o menor valor de vazão alcançado foi de 0,62 $\mathrm{m} 3 / \mathrm{s}$ no mês de agosto de 2012, enquanto que o maior foi de $1,37 \mathrm{~m} 3 / \mathrm{s}$ em janeiro e fevereiro de 2012 (tabela II), na estação chuvosa. Estes resultados podem estar associados a uma possível saturação do solo, que impede que a água infiltre e passe a escoar, visto que as chuvas são de maiores intensidade neste período.

Tabela II: Resultados da altura da lâmina de água e vazão na Estação Médio Curso

\begin{tabular}{ccc}
\hline \hline Data & Altura (cm) & Vazão $\left(\mathbf{m}^{\mathbf{3}} / \mathbf{s}\right)$ \\
\hline \hline Nov. / 2011 & 174 & 0,78 \\
Jan. / 2012 & 192 & 1,37 \\
Fev. / 2012 & 186 & 1,37 \\
Mar. / 2012 & 186 & 1,18 \\
Abr. / 2012 & 129 & 1,02 \\
Mai. / 2012 & 134 & 1,33
\end{tabular}


Jun. / 2012

Ago. / 2012

Set. / 2012

Out. / 2012

Nov. / 2012
131

131

134

125

130
0,85

0,62

0,64

0,73

0,83

A curva-chave desta estação (figuraVIII) apresentou como equação:y $=32829 \times 5$ $164591 \times 4+324359 x 3-313690 x 2+148757 x-2752$. Através da equação supracitada, obtevese um índice baixo de determinação, ou seja, $\mathbf{R}^{2}=0,5437$. Este resultado está associadoà obra de dragagem ocorrida no mês de abril/2012, que aprofundou o leito, alterando o nível de base local, e por conseguinte, a dinâmica fluvial. De acordo com Cunha (1995), o aprofundamento do canal pela draga abaixa o nível de base local, desencadeando a retomada erosiva nos afluentes, além dessas intervenções desajustarem o regime de descarga e os seus intervalos de recorrência (WOLMAN \& MILLER,1960).

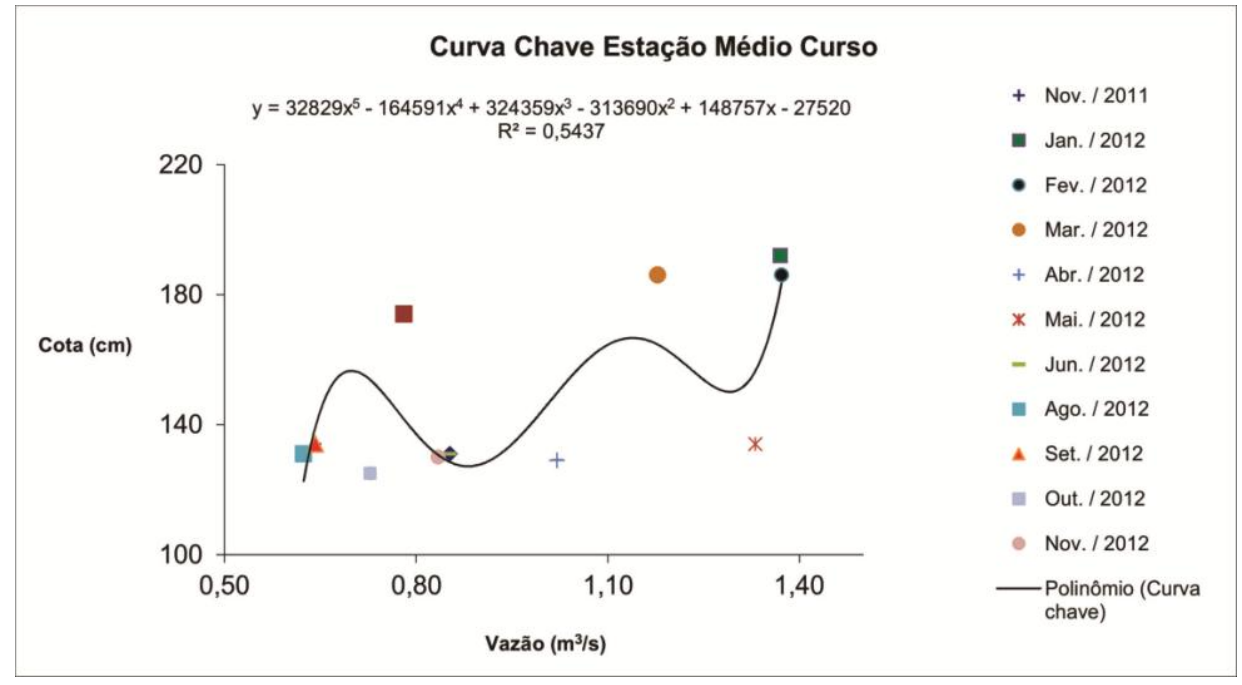

Figura VIII: Curva-Chave do rio Córrego Sujo (Estação Médio Curso)

No estudo de Brum (2010) foi adotado a mesma metodologia no mesmo ponto amostral, durante os anos de 2008 a 2010, totalizando 13 medições de vazão. O autor alcançou um elevado coeficiente de determinação $\left(\mathrm{R}^{2}=0,983\right)$ atribuindo a esta estação uma morfologia do canal mais estável e alargada, apresentando reduzidos índices de assoreamentos ou erosão. Desta forma, ratifica-se que a dragagem alterou as condições do canal, influenciando no valor de correlação.

Estes resultados também são observados nos estudos de Alpino Rodrigueset al (2012) em que há umatendência do canal escavar mais a margem direita e depositar na margem esquerda, onde estão localizadas as réguas, esta situação é proeminente ao observar o perfil 
transversalrelativo à de março de 2012. No entanto, em maio de 2012, dois meses após ocorrer à dragagem, o perfil transversal mostrou que houve um aprofundamento expressivo na margem direita e um rebaixamento no nível do rio na margem esquerda.

Com a dragagem a tendência é que a geomorfologia do canal seja constantemente alterada,uma vez que o material retirado do fundo do rio foi depositado em suas margens e a mata ciliar também foi retirada. Nesse sentido, esse material tende a ser depositado no fundo do canal, durante os eventos chuvosos, causando futuramente o seu assoreamento. Para tanto, se faz necessário o contínuo monitoramento dessas mudanças que serão refletidas na vazão fluvial.

Para a Estação Baixo Curso foi obtido a seguinte equação polinomial para a curva-chave: $\mathrm{y}=1370,4 \mathrm{x} 5-7210,5 \mathrm{x} 4+14430 \mathrm{x} 3-13609 \mathrm{x} 2+6010,1 \mathrm{x}-874,08$. A tabela III demonstra os resultados da altura da lâmina de água e os resultados referentes à vazão na estação Baixo Curso. Já a figura IX demonstra o índice de determinação obtido, que mostrou-se elevado, ou seja, de $\mathrm{R}^{2}=0,8525$.

Já a vazão apresentou máxima de 1,68 m3/s em março de 2012, ainda na estação chuvosa, e mínima de 0,40 m3/s em setembro de 2012. As vazões médias em cada ponto elevaram-se de montante para jusante, com 0,13 m3/s, 0,97 m3/s e 1,02 m3/s, de acordo com as Estações Alto, Médio e Baixo Curso respectivamente. Constata-se que, a última delas por se encontrar no exutório da bacia sofre influência das elevações de vazão do rio Preto, que se localiza 300 metros a montante deste ponto.

TabelaIII: Resultados da altura da lâmina de água e vazão na Estação Baixo Curso

\begin{tabular}{ccc}
\hline \hline Data & Altura (cm) & Vazão $\left(\mathbf{m}^{\mathbf{3}} / \mathbf{s}\right)$ \\
\hline \hline Nov. / 2011 & 108 & 0,79 \\
Jan. / 2012 & 142 & 1,39 \\
Fev. / 2012 & 136 & 1,39 \\
Mar. / 2012 & 138 & 1,68 \\
Abr. / 2012 & 136 & 1,25 \\
Mai. / 2012 & 134 & 1,17 \\
Jun. / 2012 & 124 & 1,38 \\
Ago. / 2012 & 110 & 0,67 \\
Set. / 2012 & 105 & 0,40 \\
Out. / 2012 & 124 & 0,65 \\
Nov. / 2012 & 124 & 0,54 \\
\hline \hline
\end{tabular}




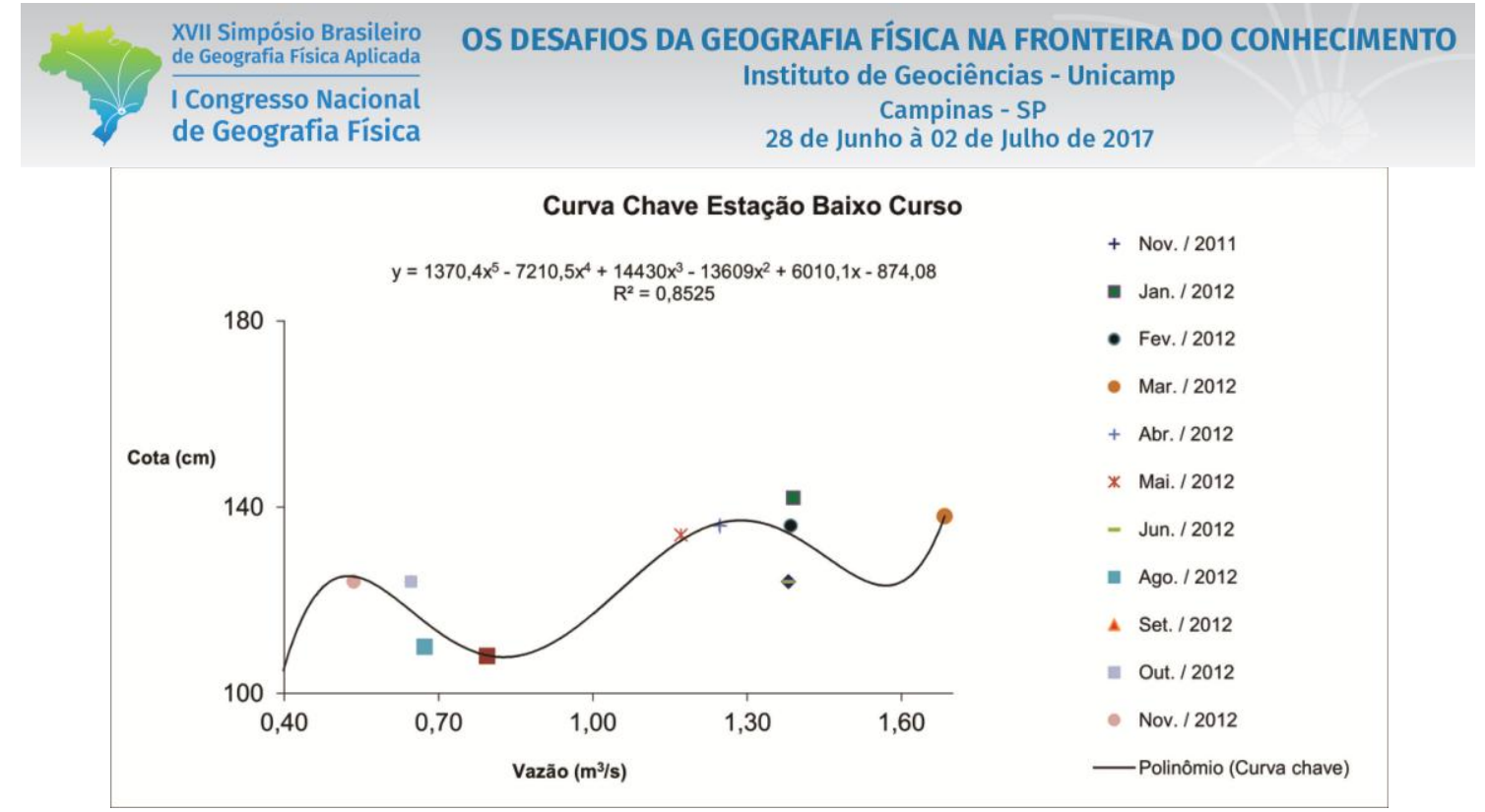

Figura IX: Curva-Chave do rio Córrego Sujo (Estação Baixo Curso)

\section{4) Conclusão}

A partir da análise da precipitação, altura linimétrica e vazão dos canais, observa-se uma estação seca que perpassa entre os meses de maio a setembro de 2012, apresentando um fluxo de base de vazão nos canais mínimo, necessitando desta forma, de planejamento, uma vez que já existem os conflitos entre os agricultores pelo uso da água.Todavia, os meses de outubro a fevereiro marcam a estação chuvosa, que contribuiu para a elevação da vazão nos respectivos canais, assim como dos fluxos de base.

Conforme já supracitado Brum (2010) identificou na estação instalada no Médio Curso o coeficiente de correlação no valor de $98 \%$, o que segundo o autor conferiu maior confiabilidade para futuras extrapolações da curva. No presente estudo, este coeficiente também foi elevado: $85 \%$. Nesse sentido, é possível prever o comportamento da vazão do canal diante de períodos de chuvas de maior intensidade ou estiagem prolongada, com a finalidade também de minimizar os conflitos pelo uso da água em épocas de seca. As informações geradas a partir dos dados fluviométricos são indispensáveis para o planejamento territorial e do uso dos recursos hídricos.

\section{Referências bibliográficas}

ALLAN, David. Stream Ecology: Structure and function of running waters.London: Chapman \& Hall, 1995.

ALPINO RODRIGUES, S. O.; BRUM, L. B. ; ARAUJO, P. C. ; COSTA, V. S. ; AVELAR, A. S . Efeito da dragagem na seção e na vazão do canal fluvial: bacia do Córrego Sujo, Teresópolis (RJ). In: $9^{\circ}$ SINAGEO - Simpósio Nacional de Geomorfologia, 2012, Rio de Janeiro.

BRASIL. Normas Climatológicas: 1961-1990. Brasília: MARA/ SNI/ INMET, 2009. 84 p.

BRUM, L. B. O Uso da Água pela Agricultura Irrigada na Região Serrana do Rio de Janeiro: Bacia do Córrego Sujo - Teresópolis. Dissertação de Mestrado em Geografia. Rio de Janeiro: UFRJ, 2010. 
CUNHA, S. B. Impactos das obras de engenharia sobre o ambiente biofísico da bacia do Rio São João (Rio de Janeiro Brasil). Rio de Janeiro, 415 p, 1995.

DANTAS, M. E. Mapa Geomorfológico. Projeto Rio de Janeiro. Rio de Janeiro: CPRM, 2000. CDROM.

DERISIO, J. C. Introdução ao controle de poluição ambiental. São Paulo: Oficina de Textos, 2012. $223 p$.

DUNNE, T.; LEOPOLD, L.B. Water in the environmental planning.São Francisco, W. H. Freeman and Company, 1978.

MAGALHÃES Jr., A. P. A situação do monitoramento das águas no Brasil - Instituições e Iniciativas.Revista Brasileira de Recursos Hídricos, Porto Alegre, vol.5, n. 3, p. 113-115, jul./set. 2000.

SANTOS, I. et al. Hidrometria Aplicada. Curitiba: Instituto de Tecnologia para o Desenvolvimento, 2001.

WOLMAN, M. G. E MILLER, J. C. Magnitude and frequency of forces in geomorphic processes. Journal Geology, 68:54-78, 1960. 